\author{
Lise Piquilloud \\ Didier Tassaux \\ Emilie Bialais \\ Bernard Lambermont \\ Thierry Sottiaux \\ Jean Roeseler \\ Pierre-François Laterre \\ Philippe Jolliet \\ Jean-Pierre Revelly
}

\section{Neurally adjusted ventilatory assist (NAVA) improves patient-ventilator interaction during non-invasive ventilation delivered by face mask}

Received: 19 December 2011

Accepted: 16 June 2012

Published online: 3 August 2012

(C) Copyright jointly held by Springer and ESICM 2012

Electronic supplementary material

The online version of this article (doi:10.1007/s00134-012-2626-9) contains supplementary material, which is available to authorized users.

L. Piquilloud ( $\bullet) \cdot$ P. Jolliet · J.-P. Revelly Intensive Care and Burn Unit,

University Hospital of Lausanne (CHUV),

Lausanne, Switzerland

e-mail: lise.piquilloud@chuv.ch

Tel.: +41-79-5567642

Fax: +41-21-3141634

P. Jolliet

e-mail: philippe.jolliet@chuv.ch

D. Tassaux

Intensive Care Unit, University Hospital of Geneva (HUG), Geneva, Switzerland

E. Bialais · J. Roeseler · P.-F. Laterre Intensive Care Unit, University Hospital St-Luc, Brussels, Belgium

B. Lambermont

Medical Intensive Care Unit,

CHU Liege, Liege, Belgium
T. Sottiaux Intensive Care Unit, Clinique Notre Dame de Grâce, Gosselies, Belgium

Abstract Purpose: To determine if, compared to pressure support (PS), neurally adjusted ventilatory assist (NAVA) reduces patient-ventilator asynchrony in intensive care patients undergoing noninvasive ventilation with an oronasal face mask.

Methods: In this prospective interventional study we compared patient-ventilator synchrony between PS (with ventilator settings determined by the clinician) and NAVA (with the level set so as to obtain the same maximal airway pressure as in PS). Two 20-min recordings of airway pressure, flow and electrical activity of the diaphragm during PS and NAVA were acquired in a randomized order. Trigger delay $\left(T_{\mathrm{d}}\right)$, the patient's neural inspiratory time $\left(T_{\text {in }}\right)$, ventilator pressurization duration $\left(T_{\text {iv }}\right)$, inspiratory time in excess $\left(T_{\text {iex }}\right)$, number of asynchrony events per minute and asynchrony index (AI) were determined. Results: The study included 13 patients, six with COPD, and two with mixed pulmonary disease. $T_{\mathrm{d}}$ was reduced with NAVA: median $35 \mathrm{~ms}$ (IQR $31-53 \mathrm{~ms})$ versus $181 \mathrm{~ms}$ (122-208 ms); $p=0.0002$. NAVA reduced both premature and delayed cyclings in the majority of patients, but not the median $T_{\mathrm{iex}}$ value. The total number of asynchrony events tended to be reduced with NAVA: 1.0 events/min $(0.5-3.1$ events/min) versus 4.4 events $/ \mathrm{min}$ (0.9-12.1 events $/ \mathrm{min}) ; p=0.08$. AI was lower with NAVA: $4.9 \%$ $(2.5-10.5 \%)$ versus $15.8 \%(5.5-49.6$ $\%) ; p=0.03$. During NAVA, there were no ineffective efforts, or late or premature cyclings. $\mathrm{PaO}_{2}$ and $\mathrm{PaCO}_{2}$ were not different between ventilatory modes. Conclusion: Compared to PS, NAVA improved patient ventilator synchrony during noninvasive ventilation by reducing $T_{\mathrm{d}}$ and AI. Moreover, with NAVA, ineffective efforts, and late and premature cyclings were absent.

Keywords Patient-ventilator interaction · Patient-ventilator synchrony $\cdot$ Noninvasive Ventilation . Pressure support · Neurally adjusted ventilatory assist

\section{Introduction}

Noninvasive pressure support ventilation (PS-NIV) is widely used to treat acute respiratory failure of various etiologies $[1,2]$ and to avoid reintubation in patients at risk of postextubation respiratory failure [3]. Because patient and ventilator respiratory profiles differ, patientventilator asynchronies often occur during pressure 
support ventilation (PS) $[4,5]$. They are particularly frequent during PS-NIV because unavoidable leaks at the patient-ventilator interface interfere with pneumatic triggering (i.e. pressure or flow triggering) and cycling-off [6]. As asynchronies are related to poor tolerance and increased risk of NIV failure [7], reducing asynchronies during NIV is a major issue. Under bench testing conditions, dedicated NIV modes decrease the number of asynchronies [8]. However, the ability of NIV modes to reduce asynchronies varies between ventilators [8], and dedicated NIV modes fail to decrease the total number of patient-ventilator asynchronies in intensive care patients [9].

Even if ventilators specially dedicated to NIV are more efficient than standard intensive care ventilators in reducing asynchronies [10], no currently available technology can prevent their occurrence during PS-NIV. However, when delivering PS-NIV through a helmet, neural triggering has been shown to improve patient-ventilator synchrony compared to pneumatic triggering [11]. As neurally adjusted ventilatory assist (NAVA) [12] uses a neural signal (the diaphragm electrical activity, or EAdi, independent from airway pressure and flow signals), to trigger and cycle-off the ventilator as well as to adapt the amount of pressure delivered, and as NAVA improves patient-ventilator interaction during invasive ventilation [13-16], we hypothesized that NAVA could improve patient-ventilator synchrony during NIV. The purpose of this study was to test this hypothesis in adult intensive care patients requiring NIV because of acute respiratory failure or because of being at risk of respiratory failure after extubation [3].

\section{Materials and methods}

This was a prospective interventional study. Patients in the intensive care units of two university hospitals (Liege and Brussels, Belgium) were included. The study protocol was approved by both ethics committee.

\section{Patients}

Intensive care patients receiving NIV via an oronasal face mask for acute respiratory failure $[17,18]$ or for being at risk of postextubation respiratory failure according to previously published criteria [3] were eligible for inclusion in the study. Exclusion criteria are outlined in the Electronic Supplementary Material.

\section{Ventilator and masks}

Patients were ventilated with a Servo-i ventilator (Maquet Critical Care, Solna, Sweden) equipped with the commercially available version (v. 5.00.00) of the NAVA software. PS and NAVA were both delivered using the invasive version of the ventilator software. Oronasal face masks (Vygon, Ecouen, France) were used to deliver NIV.

\section{Recordings}

Respiratory parameters were recorded from the ventilator using the Servo-tracker recording system. Recording methods and recorded parameters are described in the Electronic Supplementary Material.

\section{Measurements}

Trigger delay $\left(T_{\mathrm{d}}\right)$ was defined as the time difference between the initial increase in the EAdi (visually determined) and the beginning of ventilator inspiratory flow. Neural inspiratory time $\left(T_{\text {in }}\right)$ was defined, according to previously published NAVA studies [13-15, 19], as the time difference between the initial increase and the maximal value of EAdi (EAdi ${ }_{\max }$ ). Details on this point are given in the Electronic Supplementary Material. Ventilator pressurization time $\left(T_{\text {iv }}\right)$ was defined as the time difference between the beginning and the end of inspiratory flow, and inspiratory time in excess $\left(T_{\mathrm{iex}}\right)$ was calculated as the time difference between the end of $T_{\mathrm{iv}}$ and $T_{\mathrm{in}}$.

From the recorded curves, the numbers of the five types of patient-ventilator asynchronies as defined by Thille et al. [5] were determined. In contrast to the study of Thille et al., EAdi was used in addition to airway pressure and flow curves to define asynchrony events [13]. This approach allows a more accurate definition of asynchrony events in relation to $T_{\text {in }}$ and is more sensitive in detecting asynchrony events during PS. Moreover, during NAVA, we considered an additional asynchrony type as a specific type of autotriggering event. This new asynchrony, called pseudotriggering, was defined as the presence of a significant (higher than $50 \%$ of the positive end expiratory pressure, PEEP, value) ventilator-delivered pressurization occurring in the absence of a typical concomitant EAdi signal indicating true respiratory diaphragmatic activity. Patient-ventilator asynchronies are described in detail and illustrated in the Electronic Supplementary Material. Asynchronies are expressed as the number of events per minute and as the asynchrony index (AI) as defined by Thille et al. [5], that is the number of events per minute divided by the sum of triggered and nontriggered breaths. An AI of more than $10 \%$ was considered as severe asynchrony [5].

Leaks were defined as the difference between inspiratory tidal volume $\left(\mathrm{VT}_{\mathrm{i}}\right)$ and expiratory tidal volume $\left(\mathrm{VT}_{\mathrm{e}}\right)$ obtained by integration of the flow curve. $\mathrm{VT}_{\mathrm{i}}, \mathrm{VT}_{\mathrm{e}}$ and leaks were measured for one respiratory cycle every $50 \mathrm{~s}$, and are reported in fractions of $\mathrm{VT}_{\mathrm{i}}$ and in liters per minute. 


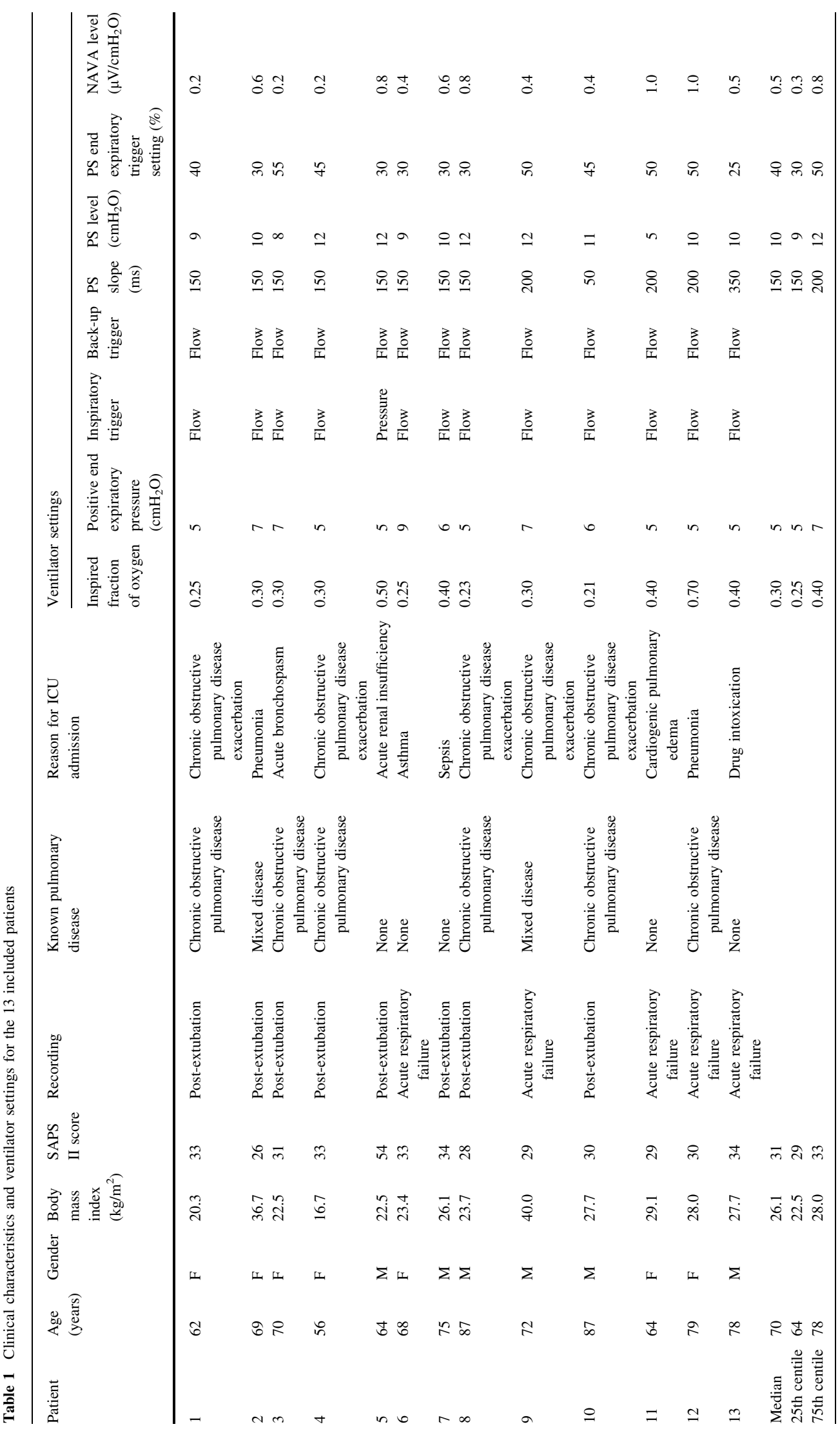


For both PS and NAVA, the measured parameters were determined over a 10 -min period randomly selected from the whole recorded period.

\section{Experimental protocol}

After written informed consent had been obtained, an $8 \mathrm{~F}$ adult NAVA nasogastric tube $(16 \mathrm{~mm}$ interelectrode distance and $125 \mathrm{~cm}$ long) was positioned and checked according to the manufacturer's recommendations [20]. Approximately $30 \mathrm{~min}$ after placement of the nasogastric tube, two sequential 20-min periods of NIV were recorded in a randomized order, one during PS as set by the clinician in charge of the patient and one during NAVA. Because NIV modes had failed to reduce the total number of asynchrony events in a previous study [9], the dedicated NIV mode was not used by the clinicians during PS-NIV according to their usual clinical practice. Similarly, during NAVA, the invasive NAVA software (NAVA ventilation without leak compensation) was used. During PS, the PS level (PSlevel), inspiratory trigger and expiratory cycling-off criterion (expiratory trigger setting, ETS) were kept constant during the entire recording. The manufacturer's recommendations were used to standardize the NAVA level setting. The NAVA level was set so as to obtain the same peak airway pressure as the total inspiratory pressure selected by the clinician during PS. The NAVA level was kept constant during the whole recording. The NAVA trigger was set at $0.5 \mu \mathrm{V}$ for all patients. PEEP and inspired fraction of oxygen $\left(\mathrm{FIO}_{2}\right)$ were the same during PS and NAVA. The built-in back-up security system for NAVA was set by default (PSlevel $20 \mathrm{cmH}_{2} \mathrm{O}$, inspiratory flow trigger $1.2 \mathrm{l} / \mathrm{min}$ and ETS $30 \%$ ).

\section{Statistics}

PS and NAVA were compared using a paired $t$-test or a paired Wilcoxon test on ranks when required. Normality was assessed using the Shapiro-Wilk test. Statistics were computed using JMP 8.0.1 statistical package (SAS, Cary, NC). For all statistical tests, a $p$ value of less than 0.05 was considered significant. Results are reported as medians (interquartile ranges, IQR) or mean $\pm \mathrm{SD}$ depending on the normality of their distribution.

\section{Results}

The study included 13 patients, 6 (46.2 \%) with known chronic obstructive pulmonary disease and $2(15.4 \%)$ with mixed obstructive and restrictive pulmonary disease. Five patients $(38.5 \%)$ required NIV because of acute respiratory failure and eight patients $(61.5 \%)$ required NIV because of being at risk of developing expiratory failure after extubation. The patients' clinical characteristics and ventilator settings are shown in Table 1. The patients' inspiratory demand and related EAdi amplitude were relatively high with a mean value of $33 \pm 17 \mu \mathrm{V}$ during PS-NIV and $33 \pm 15 \mu \mathrm{V}$ during NAVA-NIV. Probably because of this high EAdi amplitude, there were few artifacts in the recordings. During NAVA, EAdi was used to trigger $85 \pm 10 \%$ and to cycle-off $93 \pm 4 \%$ of breaths.

\section{Leaks}

Leaks were not different between PS and NAVA: $14 \%$ $\mathrm{VT}_{\mathrm{i}}\left(\mathrm{IQR} 10-21 \% \mathrm{VT}_{\mathrm{i}}\right.$ ) versus $15 \% \mathrm{VT}_{\mathrm{i}}$ (IQR 10-24\% $\mathrm{VT}_{\mathrm{i}}$ ), corresponding to $2.9 \pm 3 \mathrm{l} / \mathrm{min}$ during $\mathrm{PS}$ and $2.7 \pm 1.6 \mathrm{l} / \mathrm{min}$ during NAVA $(p=0.89)$.

$T_{\mathrm{d}}$ and $T_{\text {iex }}$

$T_{\mathrm{d}}$ and $T_{\text {iex }}$ for all patients are shown in Fig. 1. As shown in Table 2 , median $T_{\mathrm{d}}$ was significantly reduced during NAVA. $T_{\mathrm{d}}$ was $5 \%$ (IQR 4-6\%) of $T_{\text {in }}$ during NAVA and $26 \%(22-27 \%)$ during PS. Median $T_{\mathrm{iex}}$ was not different between the two modes. During PS, negative $T_{\text {iex }}$ values related to premature cycling were between -440 and $-10 \mathrm{~ms}$. Positive $T_{\mathrm{iex}}$ values related to prolonged ventilator pressurization were between +10 and $+2,170 \mathrm{~ms}$.

\section{Asynchronies}

Individual results for asynchrony events and AI are given in Fig. 1. The total number of asynchrony events tended to be reduced during NAVA compared to PS: median 4.4 events/min (IQR 0.9-12.1) during PS versus 1.0 events/min (IQR 0.5-3.1) during NAVA $(p=0.08)$. AI was significantly lower during NAVA with a median value of $4.9 \%$ (IQR 2.5-10.5\%) versus $15.8 \%$ $(5.5-49.6 \%)$ during PS $(p=0.03)$. AI was higher than $10 \%$ in 9 of 13 patients $(69.2 \%)$ during PS and only in 3 of 13 patients $(23.1 \%)$ during NAVA.

During NAVA, we observed no ineffective efforts, delayed cyclings or premature cyclings.

\section{Other respiratory parameters}

$T_{\text {in }}$ was not different between PS and NAVA: median $698 \mathrm{~ms}$ (IQR 589-874 ms) during PS and $718 \mathrm{~ms}$ (IQR $572-882 \mathrm{~ms})$ during NAVA $(p=0.19)$. Minute ventilation, $\mathrm{VT}_{\mathrm{i}}$, ventilator respiratory rate, mean airway pressure, EAdi $_{\text {max }}$ and blood gas values were the same for both modes (Table 3). 


\section{Discussion}

Our study showed that NAVA improved patient-ventilator synchrony during NIV by reducing $T_{\mathrm{d}}$ and severe asynchrony compared with PS. Additionally, there were no ineffective efforts, no delayed cycling and no premature cycling during NAVA. These results are consistent with improved synchrony demonstrated in animals [21] and in low-birth-weight infants (using a single nasal prong interface) [22] with NAVA-NIV in comparison to PS-NIV as well as with improved synchrony recently demonstrated with helmet NAVA-NIV in comparison to helmet PS-NIV [23].

Before discussing the results, several limitations of the study must be addressed. First, during PS-NIV, the dedicated NIV mode was not activated. This could potentially have increased the beneficial effect of NAVA on patientventilator synchrony as compared to PS-NIV. However, as shown in a previous study, NIV modes do not succeed in reducing the total number of patient-ventilator asynchronies [6]. Second, as the presence of a nasogastric tube can potentially worsen leaks, this could theoretically have adversely influenced patient-ventilator synchrony during PS. However, in our patients, leak volume during PS
$(2.9 \pm 3 \mathrm{l} / \mathrm{min})$ was lower than previously reported values for PS-NIV [6, 9], despite the presence of NAVA nasogastric tubes. Third, since during PS-NIV settings were defined by the clinicians according to their usual procedures, the optimization of expiratory trigger, PSlevel and pressurization ramp can be questioned. According to previous reports, this could have influenced patient-ventilator synchrony during PS-NIV [24, 25]. However, as the median PSlevel was relatively low (median $10 \mathrm{cmH}_{2} \mathrm{O}, \mathrm{IQR} 9-12 \mathrm{cmH}_{2} \mathrm{O}$ ), over-assist and possibly related asynchronies would have been very unlikely. Additionally, the expiratory trigger was set at $45 \%$ (IQR $41-49 \%)$ in the subgroup of patients with known obstructive pulmonary disease, which is in line with published recommendations [25]. The ramp was determined pragmatically aiming at the most rapid pressurization tolerated while avoiding excessive face leaks and patient discomfort. According to Prinianakis et al., such ramps settings (maximum $350 \mathrm{~ms}$ in 1 of 13 patients) have a limited effect on $T_{i}$ and intrinsic PEEP [26]. Fourth, despite having set the NAVA level according to the manufacturer's procedure and because of very different airway pressure profiles during PS and NAVA [13], the comparability of assistance levels in PS and
Fig. 1 Various parameters of patient-ventilator synchrony in all patients. $P S$ pressure support, NAVA neurally adjusted ventilatory assist, epm events per minute
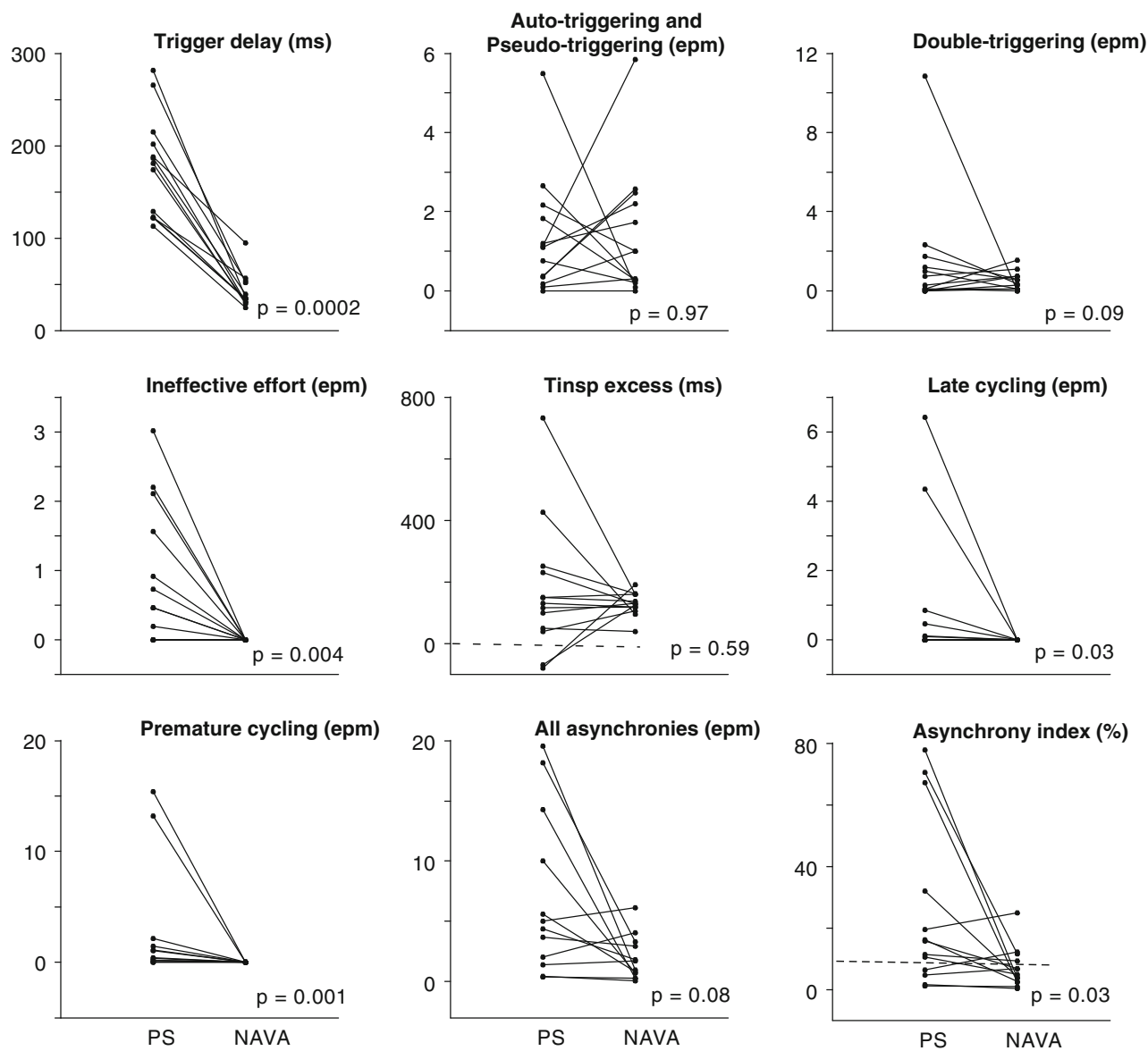
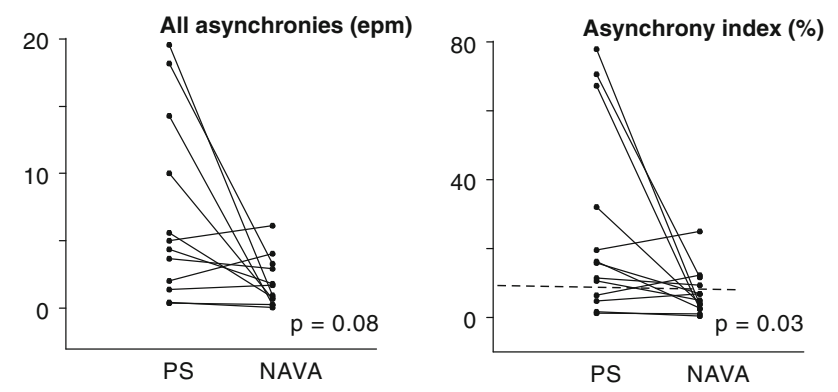
Table 2 Trigger delay, inspiratory time in excess and number of total and specific asynchronies per minute

\begin{tabular}{llll}
\hline & PS & NAVA & $p$ value \\
\hline$T_{\mathrm{d}}(\mathrm{ms})$ & $181(122-208)$ & $35(31-53)$ & 0.0002 \\
$T_{\text {iex }}(\mathrm{ms})$ & $131(44-240)$ & $129(111-159)$ & 0.59 \\
$\begin{array}{c}\text { Ineffective efforts } \\
\quad(\text { events/min) }\end{array}$ & $0.5(0-1.8)$ & $0(0-0)$ & 0.004 \\
$\begin{array}{c}\text { Late cyclings } \\
\quad(\text { events/min) }\end{array}$ & $0(0-0.7)$ & $0(0-0)$ & 0.03 \\
$\begin{array}{c}\text { Double triggerings } \\
\quad(\text { events/min) }\end{array}$ & $0.3(0-1.5)$ & $0.4(0.1-0.7)$ & 0.59 \\
$\begin{array}{c}\text { Premature cyclings } \\
\quad(\text { events/min) }\end{array}$ & $0.4(0.1-1.8)$ & $0(0-0)$ & 0.001 \\
$\begin{array}{c}\text { Autotriggerings in PS/ } \\
\text { pseudo triggerings in }\end{array}$ & $1.1(0.3-2.0)$ & $1(0.2-2.3)$ & 0.97 \\
$\quad \begin{array}{l}\text { NAVA (events/min) } \\
\text { Total asynchronies } \\
\quad(\text { events/min) }\end{array}$ & $4.4(0.9-12.1)$ & $1.0(0.5-3.1)$ & 0.08 \\
AI (\%) & $15.8(5.5-49.6)$ & $4.9(2.5-10.5)$ & 0.03
\end{tabular}

Values are medians (IQR)

$T_{\mathrm{d}}$ trigger delay, $T_{\mathrm{iex}}$ inspiratory time in excess, $A I$ asynchrony index

Table 3 Respiratory parameters and arterial blood gas

\begin{tabular}{|c|c|c|c|}
\hline Parameter & PS & NAVA & $p$ \\
\hline $\begin{array}{l}\text { Minute ventilation } \\
\text { (1/min) }\end{array}$ & $15.2 \pm 3.9$ & $15.6 \pm 4.4$ & 0.57 \\
\hline $\begin{array}{l}\mathrm{VT}_{\mathrm{i}}(\mathrm{ml} / \mathrm{kg} \text { ideal } \\
\text { body weight })\end{array}$ & $9.1 \pm 1.5$ & $10.0 \pm 2.4$ & 0.24 \\
\hline Leaks $(1 / \mathrm{min})$ & $2.9 \pm 3.0$ & $2.7 \pm 1.6$ & 0.89 \\
\hline $\begin{array}{l}\text { Ventilator respiratory } \\
\text { rate (cycles/min) }\end{array}$ & $27.4 \pm 5.4$ & $26.3 \pm 6.2$ & 0.39 \\
\hline $\begin{array}{l}\text { Mean airway } \\
\text { pressure }\left(\mathrm{cmH}_{2} \mathrm{O}\right)\end{array}$ & $8.8 \pm 1.3$ & $8.8 \pm 1.8$ & 0.93 \\
\hline EAdi $_{\max }$ & $33 \pm 17$ & $33 \pm 15$ & 0.97 \\
\hline $\mathrm{PaO}_{2}(\mathrm{mmHg})$ & $78 \pm 19$ & $77 \pm 20$ & 0.17 \\
\hline $\mathrm{PaO}_{2} / \mathrm{FIO}_{2}$ & $245 \pm 76$ & $240 \pm 82$ & 0.25 \\
\hline $\mathrm{PaCO}_{2}(\mathrm{mmHg})$ & $53 \pm 15$ & $54 \pm 16$ & 0.58 \\
\hline $\mathrm{pH}$ & $7.37 \pm 0.08$ & $7.37 \pm 0.08$ & 0.88 \\
\hline
\end{tabular}

Values are means $\pm \mathrm{SD}$

$P S$ period of ventilation under pressure support, $N A V A$ period of ventilation under neurally adjusted ventilatory assist, $V T_{i}$ indexed tidal volume by ideal body weight in kilograms, $E_{\text {adi max }}$ maximal value of the electrical diaphragmatic activity, $\mathrm{PaO}_{2}$ arterial partial pressure of oxygen, $\mathrm{FIO}_{2}$ inspired fraction of oxygen, $\mathrm{PaCO}_{2}$ arterial partial pressure of carbon dioxide

NAVA is questionable. Fifth, the tracings were analyzed by only one investigator, which could have led to systematic bias. However, the methodology and reading criteria were strictly defined before the analysis and were identical to those used in a previous study [13]. Sixth, under each mode patient ventilator synchrony was analyzed during $10 \mathrm{~min}$ randomly selected from the 20 -min recordings. This could theoretically have influenced the results. However, as previously reported [27], patients adapt to a new ventilatory mode in less than ten respiratory cycles, so such an influence is very unlikely. Finally, the number of included patients was small and as our group of patients included those admitted for acute respiratory failure and those at risk of developing respiratory failure after extubation, the group was heterogeneous. Nonetheless, despite this heterogeneity, all patients received NIV for well-validated indications $[3,17,18]$. It must also be pointed out that our study was a short-term evaluation and that the included patients were not in severe respiratory distress.

Interestingly, in contrast to recordings during invasive ventilation [13], no artifact required the exclusion of a recorded session during NIV. This was probably related to a higher EAdi amplitude during NIV. Furthermore, there was no automatic reversion to back-up PS during NAVA throughout the study.

Regarding triggering, our results show a major reduction in $T_{\mathrm{d}}$ with NAVA compared to PS, which is in line with previous reports in intubated patients $[13,14]$. This was expected, as NAVA uses the EAdi to trigger the ventilator and as EAdi, which is the expression of the patient's inspiratory demand generated in the brainstem, occurs earlier than any flow or pressure variation used to trigger the ventilator during PS. This positive effect of NAVA on $T_{\mathrm{d}}$ could, however, potentially be reduced because of a built-in triggering system that can use either EAdi or a pneumatic signal to trigger the ventilator during NAVA on a first-come first-served basis. However, in our dataset, only $15 \%$ of the breaths were triggered by a pneumatic signal, which means that $T_{\mathrm{d}}$ was reduced during NAVA in at least $85 \%$ of all respiratory cycles. The reduction in $T_{\mathrm{d}}$ during NAVA to a value far below the conscious threshold of perception of about $150 \mathrm{~ms}$ [28] could potentially improve patient tolerance to NIV by reducing the discomfort due to the triggering process and the related feeling of dyspnea.

Of note, there were no ineffective efforts during NAVA-NIV, in contrast to PS-NIV. As ineffective efforts are related to increased work of breathing [29] and as increased work of breathing and insufficient unloading of respiratory muscles during NIV can lead to NIV failure, this point is of major clinical relevance. The ability of NAVA to reduce ineffective efforts is particularly interesting for patients with chronic obstructive pulmonary disease who exhibit a high number of ineffective efforts related to the inspiratory threshold load associated with intrinsic PEEP when flow or pressure triggering is used [30]. Despite NAVA improving the triggering process, we noted that it did not suppress double triggering. However, in contrast to the findings of our study on NAVA during invasive ventilation [13], we found no increase in double triggering under NAVA-NIV. This difference can probably be explained by the fact that EAdi amplitude during NIV was higher, thus reducing the vulnerability to artifacts in the EAdi signal and the consecutive generation of double triggering. An unsolved problem with NAVA related to the triggering process is the possible occurrence 
of autotriggering events (called pseudotriggerings) due to the fact that during NAVA ventilator pressurization is initiated in response to each increase in EAdi including increases due to signal artifacts or to any kind of "subrespiratory" diaphragmatic activity. However, in our dataset there was no increase in autotriggering events in comparison to PS. Moreover, as pseudotriggerings during NAVA were related to lower airway pressure variations than autotriggerings during PS, their detrimental effect on the patients' respiratory pattern could be limited. We cannot exclude, however, the possibility that pseudotriggerings during NAVA could be a source of patient discomfort.

Our results show that NAVA improved the expiratory cycling by suppressing both delayed and premature cycling, which was expected because of the EAdi-based termination of pressurization. Of note, as pressurization is interrupted when the EAdi signal decreases to $70 \%$ of its maximal value, there is an expected delay between the time of the maximal EAdi value and the time of termination of pressurization, which was obvious in our results. Contrary to expectations, we found no reduction in median $T_{\text {iex }}$ during NAVA-NIV, which could be explained by the fact that the ETS selected by the clinicians during PS-NIV was adapted to the patients according to published recommendations [25]. In particular, in patients with known obstructive pulmonary disease, the ETS was set to a value of $45 \%$ (IQR $41-49 \%)$. Figure 1 shows that during NAVA, $T_{\mathrm{iex}}$ decreased in all patients with normal or obstructive respiratory mechanics. In patients with restrictive respiratory mechanics, $T_{\text {iex }}$ had a negative value during PS because of premature cycling. During NAVA, $T_{\text {iex }}$ reached a positive value in these patients, indicating the absence of premature cycling. Thus, NAVA seems to normalize both premature and delayed expiratory cycling.

If we consider the total number of asynchrony events, our results show a trend in reducing patient-ventilator asynchronies during NAVA-NIV. In our small group of patients, this reduction was not statistically significant. However, the
AI, which reflects the severity of asynchrony, was significantly reduced during NAVA. Moreover, severe asynchrony (defined as an AI of more than $10 \%$ ) was present in 9 of 13 patients $(69.2 \%)$ during PS and in only 3 of 13 patients $(23.1 \%)$ during NAVA. As severe asynchrony has been associated with increased duration of mechanical ventilation $[5,31]$ and with a poor outcome when mechanical ventilation is prolonged [31] in intubated patients, the ability of NAVA to reduce patient-ventilator asynchrony could be clinically important.

Regarding other respiratory parameters and despite improved synchrony observed with NAVA, we found no differences in $\mathrm{PaO}_{2}$, $\mathrm{pH}$ or $\mathrm{PaCO}_{2}$ after 20 min under PS or NAVA. EAdi amplitude was also the same in NAVANIV and in PS-NIV, suggesting that NAVA-NIV did not globally increase respiratory muscle unloading in comparison to PS-NIV with clinicians' ventilator settings. General limitations related to the use of NAVA during NIV are given in the Electronic Supplementary Material.

\section{Conclusions}

This study showed that NAVA can be used to deliver NIV in intensive care patients and could improve patientventilator synchrony by reducing $T_{\mathrm{d}}$ and severe asynchronies compared with PS. It also highlighted NAVA's ability to eliminate ineffective efforts, and delayed and premature cyclings. However, whether these promising physiological effects could favorably impact patient outcome remains to be determined and should be explored in large-scale randomized studies.

Acknowledgments The authors wish to thank the Swiss Society of Intensive Care Medicine research fund for its financial support and Maquet Critical Care for having provided NAVA nasogastric tubes free of charge.

\section{References}

1. Esteban A, Anzueto A, Frutos F, Alia I, Brochard L, Stewart TE, Benito S, Epstein SK, Apezteguia C, Nightingale P, Arroliga AC, Tobin MJ (2002) Characteristics and outcomes in adult patients receiving mechanical ventilation: a 28 -day international study. JAMA 287:345-355

2. Demoule A, Girou E, Richard JC, Taille S, Brochard L (2006) Increased use of noninvasive ventilation in French intensive care units. Intensive Care Med 32:1747-1755
3. Ferrer M, Valencia M, Nicolas JM, Bernadich O, Badia JR, Torres A (2006) Early noninvasive ventilation averts extubation failure in patients at risk: a randomized trial. Am J Respir Crit Care Med 173:164-170

4. Yamada Y, Du HL (2000) Analysis of the mechanisms of expiratory asynchrony in pressure support ventilation: a mathematical approach. J Appl Physiol 88:2143-2150

5. Thille AW, Rodriguez P, Cabello B, Lellouche F, Brochard L (2006) Patient-ventilator asynchrony during assisted mechanical ventilation. Intensive Care Med 32:1515-1522
6. Vignaux L, Vargas F, Roeseler J, Tassaux D, Thille AW, Kossowsky MP, Brochard L, Jolliet P (2009) Patientventilator asynchrony during noninvasive ventilation for acute respiratory failure: a multicenter study. Intensive Care Med 35:840-846

7. Carlucci A, Richard JC, Wysocki M, Lepage E, Brochard L (2001) Noninvasive versus conventional mechanical ventilation. An epidemiologic survey. Am J Respir Crit Care Med 163:874-880 
8. Vignaux L, Tassaux D, Jolliet P (2007) Performance of noninvasive ventilation modes on ICU ventilators during pressure support: a bench model study. Intensive Care Med 33:1444-1451

9. Vignaux L, Tassaux D, Carteaux G, Roeseler J, Piquilloud L, Brochard L, Jolliet P (2010) Performance of noninvasive ventilation algorithms on ICU ventilators during pressure support: a clinical study. Intensive Care Med 36:2053-2059

10. Carteaux G, Lyazidi A, CordobaIzquierdo A, Vignaux L, Jolliet $\mathrm{P}$, Thille AW, Richard JC, Brochard L (2012) Patient-ventilator asynchrony during noninvasive ventilation: a bench and clinical study. Chest. doi: 10.1378/chest.11-2279

11. Moerer O, Beck J, Brander L, Costa R, Quintel M, Slutsky AS, Brunet F, Sinderby C (2008) Subject-ventilator synchrony during neural versus pneumatically triggered non-invasive helmet ventilation. Intensive Care Med 34:1615-1623

12. Sinderby C, Navalesi P, Beck J, Skrobik Y, Comtois N, Friberg S, Gottfried SB, Lindstrom L (1999) Neural control of mechanical ventilation in respiratory failure. Nat Med 5:1433-1436

13. Piquilloud L, Vignaux L, Bialais E, Roeseler J, Sottiaux T, Laterre PF, Jolliet P, Tassaux D (2011) Neurally adjusted ventilatory assist improves patient-ventilator interaction. Intensive Care Med 37:263-271

14. Spahija J, de Marchie M, Albert M, Bellemare P, Delisle S, Beck J, Sinderby C (2010) Patient-ventilator interaction during pressure support ventilation and neurally adjusted ventilatory assist. Crit Care Med 38:518-526

15. Colombo D, Cammarota G, Bergamaschi V, De Lucia M, Corte FD, Navalesi P (2008) Physiologic response to varying levels of pressure support and neurally adjusted ventilatory assist in patients with acute respiratory failure. Intensive Care Med 34:2010-2018
16. Terzi N, Pelieu I, Guittet L, Ramakers $\mathrm{M}$, Seguin A, Daubin C, Charbonneau P, du Cheyron D, Lofaso F (2010) Neurally adjusted ventilatory assist in patients recovering spontaneous breathing after acute respiratory distress syndrome: physiological evaluation. Crit Care Med 38:1830-1837

17. Ferrer M, Esquinas A, Leon M, Gonzalez G, Alarcon A, Torres A (2003) Noninvasive ventilation in severe hypoxemic respiratory failure: a randomized clinical trial. Am J Respir Crit Care Med 168:1438-1444

18. Brochard L, Mancebo J, Wysocki M, Lofaso F, Conti G, Rauss A, Simonneau G, Benito S, Gasparetto A, Lemaire F et al (1995) Noninvasive ventilation for acute exacerbations of chronic obstructive pulmonary disease. N Engl J Med 333:817-822

19. Beck J, Gottfried SB, Navalesi P, Skrobik Y, Comtois N, Rossini M, Sinderby C (2001) Electrical activity of the diaphragm during pressure support ventilation in acute respiratory failure. Am J Respir Crit Care Med 164:419-424

20. Barwing J, Ambold M, Linden N, Quintel M, Moerer O (2009) Evaluation of the catheter positioning for neurally adjusted ventilatory assist. Intensive Care Med 35:1809-1814

21. Beck J, Campoccia F, Allo JC, Brander L, Brunet F, Slutsky AS, Sinderby C (2007) Improved synchrony and respiratory unloading by neurally adjusted ventilatory assist (NAVA) in lung-injured rabbits. Pediatr Res 61:289-294

22. Beck J, Reilly M, Grasselli G, Mirabella L, Slutsky AS, Dunn MS, Sinderby C (2009) Patient-ventilator interaction during neurally adjusted ventilatory assist in low birth weight infants. Pediatr Res 65:663-668
23. Cammarota G, Olivieri C, Costa R, Vaschetto R, Colombo D, Turucz E, Longhini F, Della Corte F, Conti G, Navalesi P (2011) Noninvasive ventilation through a helmet in postextubation hypoxemic patients: physiologic comparison between neurally adjusted ventilatory assist and pressure support ventilation. Intensive Care Med 37:1943-1950

24. Thille AW, Cabello B, Galia F, Lyazidi A, Brochard L (2008) Reduction of patient-ventilator asynchrony by reducing tidal volume during pressuresupport ventilation. Intensive Care Med 34:1477-1486

25. Tassaux D, Gainnier M, Battisti A, Jolliet P (2005) Impact of expiratory trigger setting on delayed cycling and inspiratory muscle workload. Am J Respir Crit Care Med 172:1283-1289

26. Prinianakis G, Delmastro M, Carlucci A, Ceriana P, Nava S (2004) Effect of varying the pressurisation rate during noninvasive pressure support ventilation. Eur Respir J 23:314-320

27. Viale JP, Duperret S, Mahul P, Delafosse B, Delpuech C, Weismann D, Annat G (1998) Time course evolution of ventilatory responses to inspiratory unloading in patients. Am J Respir Crit Care Med 157:428-434

28. Whitelaw WA, Derenne JP, Milic-Emili J (1975) Occlusion pressure as a measure of respiratory center output in conscious man. Respir Physiol 23:181-199

29. Kondili E, Prinianakis G, Georgopoulos D (2003) Patient-ventilator interaction. Br J Anaesth 91:106-119

30. Nava S, Bruschi C, Fracchia C, Braschi A, Rubini F (1997) Patient-ventilator interaction and inspiratory effort during pressure support ventilation in patients with different pathologies. Eur Respir J 10:177-183

31. Chao DC, Scheinhorn DJ, StearnHassenpflug M (1997) Patientventilator trigger asynchrony in prolonged mechanical ventilation. Chest 112:1592-1599 